\title{
E-commerce During Covid: Stylized Facts from 47 Economies
}

Joel Alcedo, Alberto Cavallo, Bricklin Dwyer, Prachi Mishra, and Antonio Spilimbergo*

WP/22/19

IMF Working Papers describe research in progress by the author(s) and are published to elicit comments and to encourage debate. The views expressed in IMF Working Papers are those of the author(s) and do not necessarily represent the views of the IMF, its Executive Board, or IMF management.

\section{2 JAN}

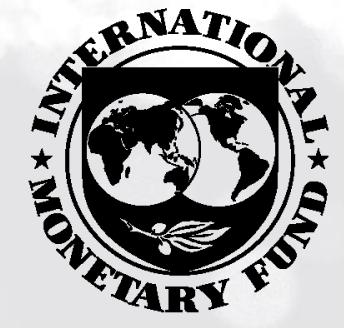




\title{
IMF Working Paper Research Department
}

\section{E-commerce During Covid: Stylized Facts from 47 Economies}

\author{
Joel Alcedo, Alberto Cavallo, Bricklin Dwyer, Prachi Mishra, and Antonio Spilimbergo* \\ Authorized for distribution by Antonio Spilimbergo \\ January 2022
}

IMF Working Papers describe research in progress by the author(s) and are published to elicit comments and to encourage debate. The views expressed in IMF Working Papers are those of the author(s) and do not necessarily represent the views of the IMF, its Executive Board, or IMF management.

\begin{abstract}
:
We study e-commerce across 47 economies and 26 industries during the COVID-19 pandemic using aggregated and anonymized transaction-level data from Mastercard, scaled to represent total consumer spending. The share of online transactions in total consumption increased more in economies with higher pre-pandemic e-commerce shares, exacerbating the digital divide across economies. Overall, the latest data suggest that these spikes in online spending shares are dissipating at the aggregate level, though there is variation across industries. In particular, the share of online spending in professional services and recreation has fallen below its pre-pandemic trend, but we observe a longer-lasting shift to digital in retail and restaurants.
\end{abstract}

JEL Classification Numbers: O3, E00, F00

Keywords: COVID-19, Technological Change, consumption, digitalization; e-commerce

Author's E-Mail Address:

aspilimbergo@imf.org; pmishra@imf.org; joel.alcedo@mastercard.com; acavallo@hbs.edu; bricklin.dwyer@mastercard.com

\footnotetext{
*Alcedo and Dwyer are at Mastercard Economics Institute, email: Joel.Alcedo@mastercard.com, Bricklin.Dwyer@mastercard.com. Cavallo is at Harvard Business School, email: acavallo@hbs.edu. Mishra and Spilimbergo are with the Research Department at the International Monetary Fund, email: pmishra@imf.org and aspilimbergo@imf.org. We thank Swapnil Agarwal for excellent research support. All errors remain our own. The views expressed here are those of the authors and do not necessarily represent those of the IMF, its Management and Executive Board, or IMF policy.
} 


\section{Introduction}

When the COVID-19 pandemic hit unexpectedly in early 2020 , there was a sudden surge in e-commerce..$^{1}$ In a matter of a few weeks, lockdowns were imposed, severely limiting physical retail purchases and increasing the pace of online purchases in most economies. But even though the increase is apparent in most economies, there are still no data available that can quantify the magnitude or the persistence of these effects at high frequency for many economies and sectors. So how much did the digitalization of consumption increase during this period? Did the shock allow economies with low e-commerce penetration to catch up, or did it increase the digital divide? Was the increase a transient blip or a permanent increase in levels or trends? Which factors can explain differences across economies and sectors?

This paper investigates these questions by leveraging a unique database provided by Mastercard $\odot$. The data cover all transactions within the Mastercard universe. ${ }^{2}$ Our sample comprises 47 economies and 26 sectors for the period between January 2018 and September $2021 .^{3}$ This reveals both online and offline patterns of spending at different levels of development for roughly 1.5 years before and after the COVID-19 pandemic started. Our main variable of interest is the share of transactions online.

We find that economies with a higher pre-COVID share of online transactions in total consumption accelerated the relative use of e-commerce, exacerbating the digital divide across economies. The latest data suggest that the spikes in online spending shares are gradually dissipating at the aggregate level. However, the aggregate data masks significant variation across industries. The increase in online spending shares is more persistent in the retail sector and restaurants, suggesting some e-commerce learning and a longer-lasting impact of social mobility restrictions in these sectors.

The rest of the paper is organized as follows. Section 2 reviews the related literature; Section 3 describes the data and provides the assumptions under which the data represents consumption patterns; Section 4 documents stylized facts to answer the questions above; section 5 concludes with tentative explanations for patterns observed in the data.

\section{Related literature}

This paper is related to the body of evidence that quantifies the benefit to consumers from the internet, including Goolsbee and Klenow, 2006; Brynjolfsson and Oh, 2012; and Varian, 2013. A paper similar to ours is Dolfen et. al. (2020), which uses transaction-level data from the United States on credit and debit cards from Visa, Inc. between 2007 and 2017, and estimates that e-commerce spending reached $8 \%$ of consumption by 2017 in the US, yielding consumers the equivalent of a $1 \%$ permanent boost to their consumption. Our paper contributes to this literature by looking at the more recent COVID period and extending the coverage of the credit and debit card data to 47 economies, although we do not consider welfare questions but rather focus on the dynamics of online spending, using the COVID-19 pandemic as a natural experiment.

Another strand of the literature looks at how e-commerce affects pricing behaviors and inflation dynamics. Cavallo (2018) shows that online competition increases the frequency of retail price changes and passthrough from aggregate shocks. Jo, Matsumura and Weinstein (2019), use data from Rakuten in Japan to show that e-commerce increased the rate of inter-city price convergence and lowered relative inflation rates for goods sold intensively online. Goolsbee and Klenow (2018) show that matched-model online inflation was more than one percent lower than in the corresponding CPI in the US during the period 20142017. Reinsdorf and Schreyer (2020) find that the overstatement of inflation may not be more than $\sim 0.5 \mathrm{pp}$ per year for OECD economies. By documenting an increase in e-commerce during COVID, our work

\footnotetext{
${ }^{1}$ For the pre-pandemic period, the U.S. Census Bureau estimates that e-commerce rose from 5 percent in 2007 to 11 percent in 2019 (https://www.census.gov/retail/index.html).

2 The universe of Mastercard refers to the "switched" universe, which goes through the process that authorizes the merchant and transaction when a payment is initiated.

${ }^{3}$ The list of 47 economies is in Table 1.
} 
suggests that some of the patterns and implications from these papers could be magnified around an exogenous shock.

Finally, our paper is part of growing literature that uses private data to improve and complement surveybased methods of economic measurement. Examples include the use of online price data for inflation measurement in Cavallo (2013) and the recent work by Chetty et al (2020) and Carvalho et al (2020) to track economic activity in real-time during COVID. ${ }^{4}$ Closer to our paper, Alandangady et al. (2019) uses credit and debit card transactions to create daily estimates of retail spending that can approximate the official Census retail surveys in the United States. Our work contributes to this literature by showing how real-time credit card data can be used to measure e-commerce sales and improve the understanding of consumption patterns during times of crisis in many economies.

\section{Data \& Methodology}

\section{Credit and Debit Card Data}

Our primary dataset is the universe of all credit and debit card transactions that were cleared through the Mastercard network between January 2018 and September 2021 in more than 200 economies and territories. ${ }^{5}$ We limit our sample to 47 economies where Mastercard has a significant market share of total card transactions. ${ }^{6}$ Across these economies, Mastercard accounted for a significant portion of credit and debit card transaction volume over the sample period. Online Appendix A provides a more detailed description of the data.

The data contain the total dollar amount of the transaction, and a sectoral classification for the merchant associated with the transaction, spanning 26 sectors and over 100 industry subcategories. The data are available at a daily frequency, allowing us to document e-commerce dynamics at a high frequency during the pandemic. While the data contain the total amount per transaction, but not the specific items purchased, nor their prices or quantities. "Online" spending is defined as a transaction where neither the cardholder nor the card are physically present. This can include a wide range of payment channels, such as the internet (through a web browser, mobile device, etc.), payment by phone or a mail-order purchase. Any transaction not online is classified as "offline".

\section{Computing the Online Share of Transactions}

For each economy in the sample, we want to estimate the "online spending share" of total consumption in economy $c$ at time $t$, given by

$$
S_{c, t}=\frac{\text { Total online spending }}{\text { Total consumption }}
$$

Under the assumption that all cash payments are offline, and that other online payment methods are negligible or ultimately processed through credit cards (eg. Paypal, Apple/Google Pay), Equation (1) can be re-written as:

$$
s_{c, t}=\frac{\text { Online card spending }}{\text { Total consumption }}
$$

We further assume that the online spending share through Mastercard is representative of online spending shares through other cards, so we can re-write (2) as

(3)

\footnotetext{
${ }^{4}$ Other important examples are Choi and Varian (2012), Einav and Levin (2014), Glaeser at al (2017), and Abraham et al (2020).

${ }^{5}$ Nilson Report issue 1199 (June 2021) noted the global share of purchase transactions for Visa at 40\%, UnionPay at 32\%, Mastercard at $24 \%$, and Rest at $4 \%$.

${ }^{6}$ Appendix $\mathrm{C}$ we show that the online share patterns are similar when we use data from economies that are below that market share threshold.
} 
Where

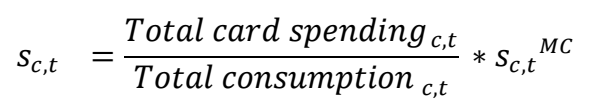

$$
s_{c, t}{ }^{M C}=\frac{\text { Online Mastercard spending }}{c, t}
$$

The online spending share $s_{c, t}$ is computed based on Equation (3). $s_{c, t}{ }^{M C}$ is calculated using monthly transaction level data from Mastercard. Total card spending $c_{c, t}$ is based on annual estimates from Mastercard. For Total consumption ${ }_{c, t}$ we use annual final private consumption expenditures collected from various sources including national statistics, Eurostat, and the IMF. We use raw series, without seasonal adjustment, for online shares for the baseline analysis, though all the findings remain similar if we adjust the data to account for seasonal patterns with standard methods.

\section{Stylized facts: heterogeneity, divergence, and transiency}

In this section we present five stylized facts on online shares across economies and sectors.

\section{Fact 1. There is significant heterogeneity in deviations from economy-wide trends}

The share of online spending differs significantly across economies in level, and trends. We report the levels at three points in time (2019 average, peak, and latest), and focus on the deviations during the COVID-19 pandemic with respect to economy-specific trends. In all cases, the pre-COVID trend is estimated in each economy using a simple regression of monthly online shares on a time trend between 2018-2019.

Figure 1 provides two diverging examples of the dynamic behavior of the online share $s_{c, t}$ in the retail sector (solid line) compared to the pre-COVID trend in each economy (dashed line). In the United States, the online share of spending in retail peaked shortly after the pandemic started, rising from $13.9 \%$ to $17.7 \%$. This share rose again towards the end of the year (when the economy was facing a third wave of COVID cases), and then fell to reach the $15 \%$ level predicted by the pre-COVID trend by May 2021. By contrast, in Brazil the online share initially had a similar pattern but peaked in early 2021 and remained significantly above the level predicted by the pre-COVID trend after more than 18 months of the pandemic.

Figure 1. Examples of Online Spending Share During COVID - Retail

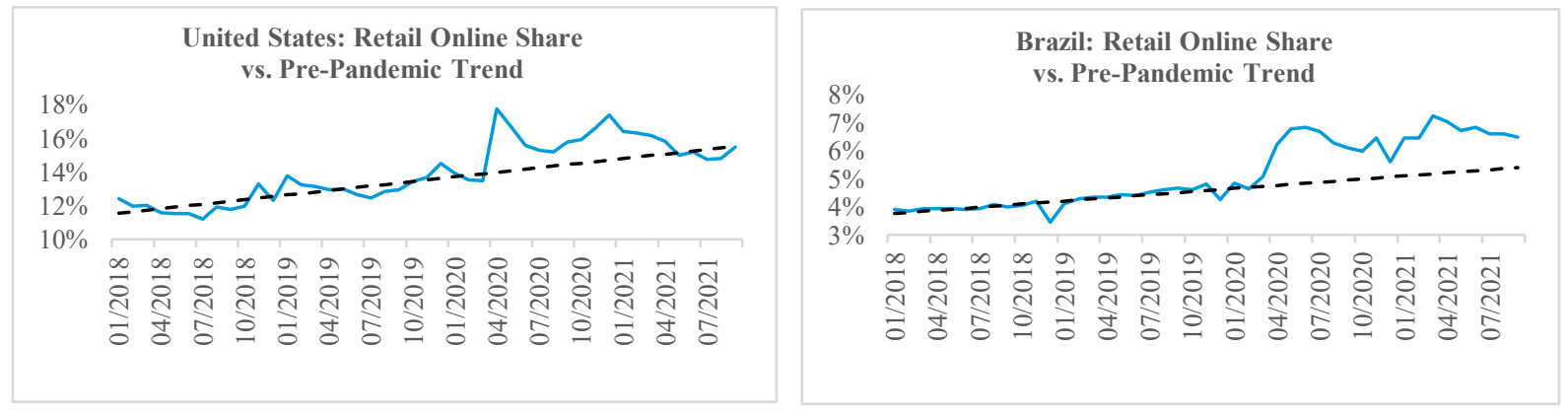

The heterogeneity is clear in Table 1, which summarizes information for our sample of 47 economies, ordered by the latest deviation relative to the pre-COVID trends. All data are in percentages and the differences are expressed as percentage points. As shown at the bottom of the table, the online share rose from $10.3 \%$ in 2019 to $14.9 \%$ at the peak, and then fell to $12.2 \%$ in 2021 . Although this level is nearly 2 percentage points higher than before the pandemic started, it is only 0.6 percentage points above the average level predicted by pre-pandemic trends.

The last column shows that most economies are now below their peak levels of online spending during the pandemic, there are still significant differences in the deviations relative to the levels predicted by the pre-pandemic trends. In about half of the economies, these deviations are still positive. This list includes some small economies such as Bahrain and Jamaica, which are the two main outliers, as well as large developing economies such as Brazil and India. In all the other economies, including the United States and many developed economies, the online shares are now either at or below the predicted pre-COVID trend levels. 
Table 1. Online Share During COVID in all Economies in the Sample

\begin{tabular}{|c|c|c|c|c|}
\hline Economy & $\begin{array}{c}2019 \\
\text { average }\end{array}$ & $\begin{array}{c}\text { Crisis peak } \\
\text { (Peak year/month) }\end{array}$ & Latest & $\begin{array}{l}\text { Latest minus pre } \\
\text { COVID trend }\end{array}$ \\
\hline Bahrain & 21.2 & $38.7(2021 / 05)$ & 34.1 & 10.0 \\
\hline Jamaica & 33.1 & $45.8(2021 / 09)$ & 43.1 & 8.3 \\
\hline New Zealand & 28.3 & $39.2(2020 / 04)$ & 29.0 & 5.1 \\
\hline Norway & 18.2 & $23.4(2021 / 09)$ & 19.7 & 4.2 \\
\hline United Kingdom & 28.4 & $39.8(2021 / 01)$ & 31.3 & 3.7 \\
\hline Singapore & 27.6 & $43.5(2021 / 09)$ & 34.7 & 3.2 \\
\hline Australia & 28.6 & $32.7(2021 / 09)$ & 32.1 & 2.0 \\
\hline Brazil & 6.7 & $10.4(2021 / 03)$ & 9.5 & 0.9 \\
\hline Malaysia & 11.7 & $19(2021 / 08)$ & 15.8 & 0.9 \\
\hline Russia & 13.2 & $21.9(2020 / 12)$ & 20.8 & 0.8 \\
\hline India & 4.4 & $7.4(2021 / 05)$ & 6.5 & 0.8 \\
\hline Croatia & 1.5 & $4.1(2020 / 12)$ & 3.0 & 0.8 \\
\hline Zimbabwe & 0.9 & $2.2(2021 / 07)$ & 1.9 & 0.8 \\
\hline Ecuador & 3.9 & $6(2021 / 04)$ & 4.6 & 0.7 \\
\hline Sweden & 10.4 & $12(2020 / 12)$ & 11.0 & 0.7 \\
\hline Montenegro & 1.2 & $3.2(2020 / 11)$ & 2.6 & 0.6 \\
\hline Italy & 5.7 & $9.9(2020 / 11)$ & 6.5 & 0.5 \\
\hline Egypt & 6.4 & $10.5(2020 / 06)$ & 10.1 & 0.5 \\
\hline Slovenia & 1.2 & $2.9(2020 / 12)$ & 1.7 & 0.4 \\
\hline Romania & 3.6 & $7(2020 / 11)$ & 5.9 & 0.4 \\
\hline Serbia & 1.2 & $2.4(2021 / 09)$ & 2.0 & 0.3 \\
\hline Slovakia & 2.0 & $3.7(2020 / 12)$ & 2.5 & 0.2 \\
\hline Argentina & 4.3 & $5.2(2021 / 05)$ & 3.9 & 0.1 \\
\hline United Arab Emirates & 13.1 & $16.6(2021 / 02)$ & 16.6 & 0.1 \\
\hline Austria & 3.5 & $7.7(2020 / 11)$ & 4.2 & 0.1 \\
\hline Hungary & 5.8 & $9.9(2021 / 03)$ & 8.5 & 0.0 \\
\hline Thailand & 9.4 & $13.7(2021 / 08)$ & 11.9 & 0.0 \\
\hline Cambodia & 1.0 & $1.4(2021 / 07)$ & 1.2 & 0.0 \\
\hline Czech Republic & 5.4 & $11.7(2021 / 03)$ & 8.0 & 0.0 \\
\hline Greece & 4.8 & $8.6(2021 / 08)$ & 6.8 & -0.1 \\
\hline Bulgaria & 3.2 & $4.9(2021 / 03)$ & 4.3 & -0.1 \\
\hline Lithuania & 3.2 & $4.8(2020 / 12)$ & 3.6 & -0.1 \\
\hline Canada & 24.4 & $33.1(2021 / 04)$ & 27.0 & -0.2 \\
\hline Poland & 2.7 & $4.1(2020 / 11)$ & 3.8 & -0.2 \\
\hline Germany & 7.1 & $12.2(2020 / 12)$ & 7.9 & -0.2 \\
\hline Dominican Republic & 4.9 & $6.7(2021 / 01)$ & 5.2 & -0.2 \\
\hline Nicaragua & 3.0 & $3.6(2021 / 09)$ & 3.0 & -0.4 \\
\hline Indonesia & 2.3 & $2.6(2021 / 07)$ & 2.5 & -0.4 \\
\hline United States & 21.6 & $25.7(2020 / 12)$ & 23.9 & -0.4 \\
\hline Philippines & 5.1 & $7.6(2021 / 09)$ & 5.9 & -0.5 \\
\hline Costa Rica & 11.3 & $14.1(2021 / 09)$ & 12.6 & -1.3 \\
\hline Netherlands & 4.0 & $5.3(2020 / 12)$ & 3.5 & -1.4 \\
\hline Barbados & 12.2 & $21.8(2021 / 09)$ & 11.3 & -2.0 \\
\hline Hong Kong & 26.0 & $34(2020 / 12)$ & 29.8 & -2.1 \\
\hline Luxembourg & 8.0 & $11.2(2020 / 11)$ & 6.6 & -2.2 \\
\hline Denmark & 31.7 & $41.1(2020 / 12)$ & 31.0 & -3.3 \\
\hline Somalia & 4.6 & $6.3(2021 / 03)$ & 3.8 & -3.9 \\
\hline Mean & 10.3 & 14.9 & 12.2 & 0.6 \\
\hline Median & 5.7 & 9.9 & 6.8 & 0.1 \\
\hline Standard Deviation & 9.6 & 13.2 & 10.9 & 2.0 \\
\hline
\end{tabular}




\section{Fact 2. Digital divergence across economies increased during the COVID-19 pandemic}

The COVID-19 crisis led to the divergence of e-commerce adoption across economies. This can be seen in Figure $2 \mathrm{a}$, where we plot the peak values relative to their contemporaneous trend predictions for all economies. Almost all economies are at or above the 45-degree green line because the peaks were higher than the levels predicted by pre-COVID trends. The fitted regression line is positively sloped, implying that economies with higher pre-COVID online shares experienced the biggest increases during the peak. A one percentage point increase in pre-COVID online shares (as predicted by the trends) is associated with an additional increase of 0.33 percentage points during the peak. Figure $2 \mathrm{~b}$ presents the same information in a different format, by plotting the difference between peak and pre-COVID trends, against the pre-COVID trend values. The positive slope in the fitted line shows that economies with higher pre-COVID shares experienced acceleration in ecommerce shares.

Figure 2. Peak versus pre-COVID trend in online spending shares across economies

Panel A. Peak vs Pre-COVID Trend

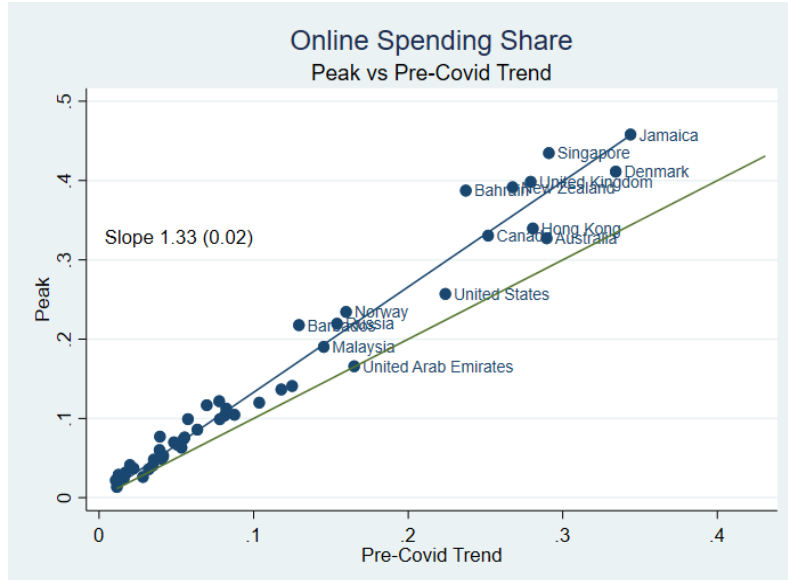

Panel B. Difference b/w Peak and Pre-COVID Trend vs Pre-COVID Trend

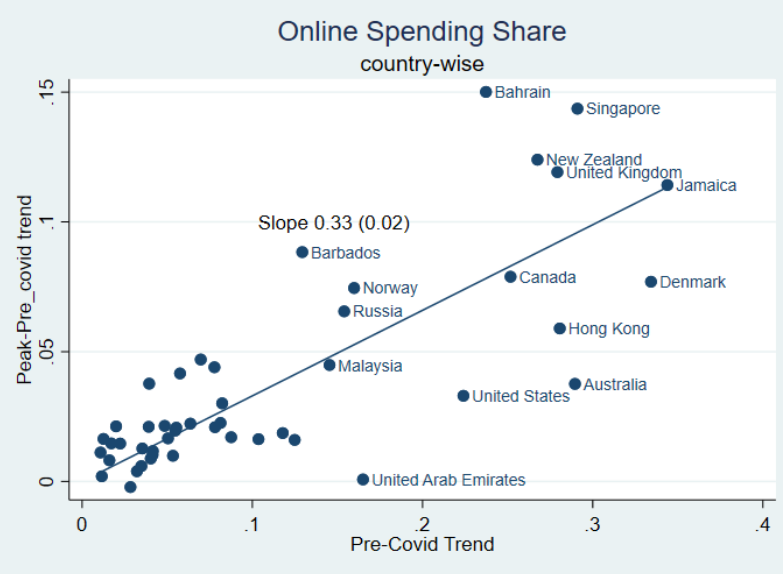

In our interpretation, these results show that COVID-19 exacerbated cross-economy digital inequality. This is what we call "digital divergence"- as opposed to the evidence for "convergence" in incomes established in the growth literature.

\section{Fact 3. The changes in online shares were mostly transitory at the aggregate level}

How persistent was the effect of COVID-19 on online transactions? We find that despite the unprecedented COVID-19 shock, much of the increase in online shares at an economy level appears to be a transitory phenomenon. This can already be seen in the aggregate statistics at the bottom of Table 1.

Figure 3 further illustrates the transitory nature of this phenomenon by taking into account the pre-COVID trends at the global level. In particular, it shows the global (weighted) average difference between the online shares and the predicted pre-crisis trends, both at the peak and with the latest data. ${ }^{7}$ While the share was 4.3 pp higher at the peak, this difference drops to 0.3 pp by September 2021. At a global level, on average, less than 7 percent of the deviation during the peak persists in the latest data.

\footnotetext{
${ }^{7}$ The average global deviation is calculated using the following 4 steps: i) calculate the deviations of the online shares from trend in each economy (as reported in Table 1), then ii) calculate the weight of each "economy-wide deviation" as the share of Mastercard spending of that economy over the total spending in the world, and iii) multiply each economy-wide deviation by the weight, using the Q3 2021 weight and (iv) compute the weighted sum which is defined as the average global deviation.
} 
Figure 3. Difference in online shares - world averages

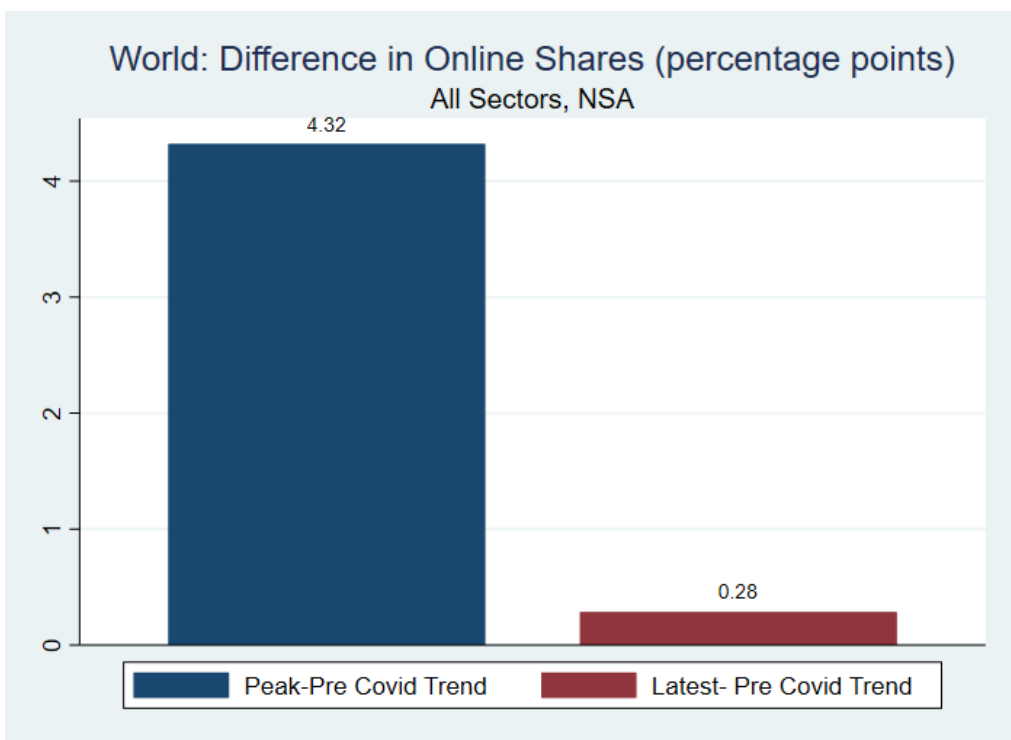

Furthermore, the digital divergence appears to be dissipating as well. In Figure 4 we repeat the computations in Figure 2, but for the latest available data. Panel A shows that the slope of the fitted regression line, though still positive, has declined significantly compared with peak shares (Figure 2a), and are now much closer to the 45-degree line. Similarly, Figure 4, Panel B plots the difference between the latest and pre-COVID trends against pre-COVID trend shares; the relationship is roughly flat, with the slope at 0.07 (compared to 0.33 in Figure 2).

Figure 4. Latest versus pre-COVID trend in online spending shares across economies

Panel A. Latest vs Pre-COVID Trend

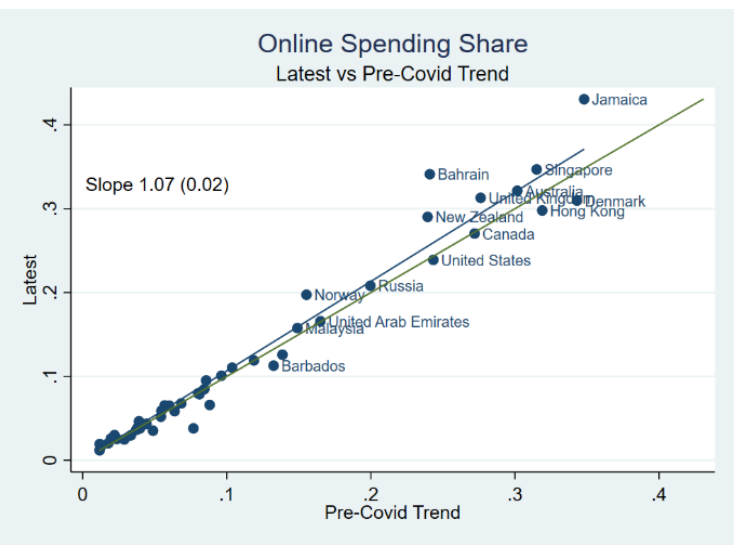

Panel B. Difference between Latest and Pre-COVID Trend vs Pre-COVID Trend

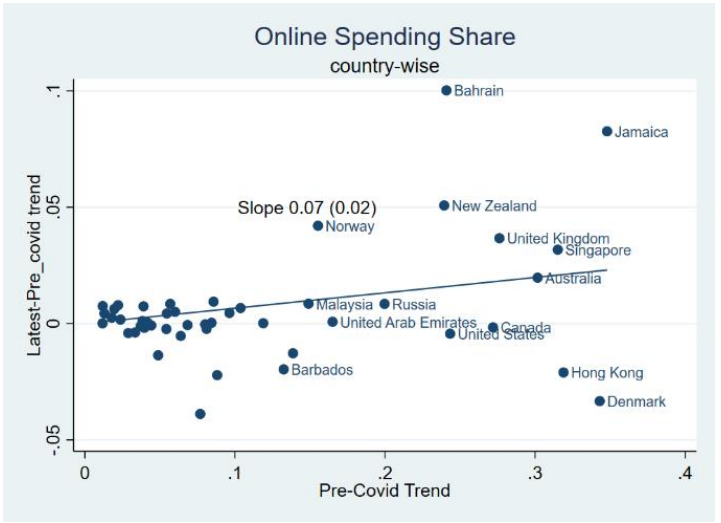

Fact 4. The deviation in online spending shares is positively correlated with mobility restrictions and fiscal spending, and negatively correlated with income per capita

What can explain the heterogeneity across economies in the level and persistence of online shares? Figure 5a shows there is a strong correlation between the economies' online shares and the strictness of the COVID-19 pandemic movement restrictions, as measured with Google's index of residential mobility. This was particularly true at the beginning of the crisis in the second quarter of 2020, when the lockdowns severely restricted mobility in most economies. However, the results in Figure $5 \mathrm{~b}$ suggest that the correlation declined as the pandemic continued. This is consistent with other research showing that the impact of COVID-19 lockdowns and other restrictions on economic activity have been declining over time. 
Figure 5. Residential mobility (time spent at home) vs. e-commerce deviation from trend

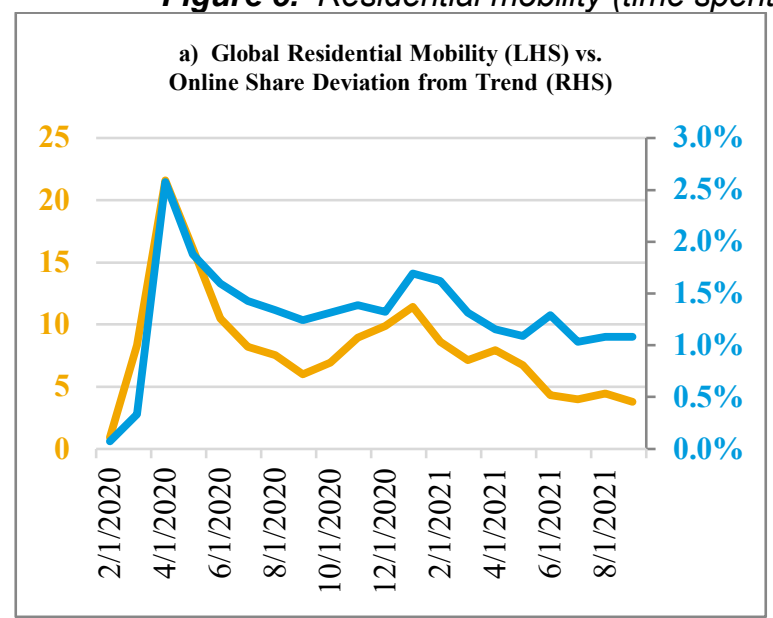

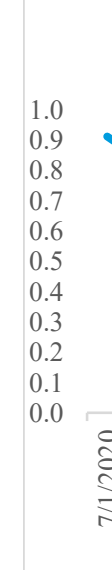

b) 6 Month Rolling Correlation between residential mobility \& eCommerce Gap

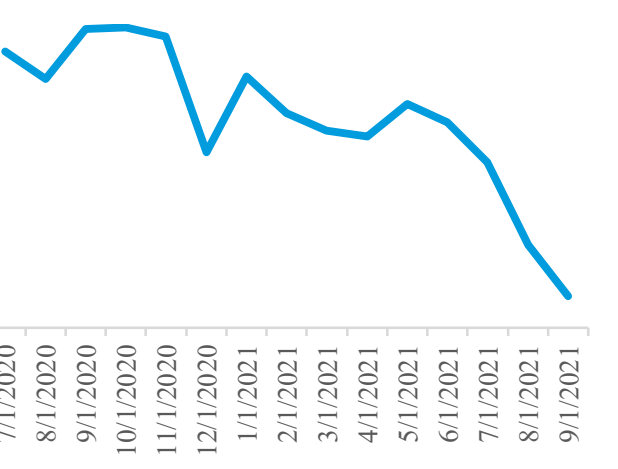

Notes: Ecommerce gaps are seasonally adjusted to account for spikes around the holidays. Both the global residential mobility and eCommerce gaps are computed by taking an equal weight average for the 47 economies in our sample.

Table 2 presents a panel regression of the deviation in online shares from the predicted pre-COVID trends on mobility, fiscal spending during COVID, and other covariates. Summary statistics for all the variables used in the regressions are reported in Table A1. Column [1] shows that after including country fixed effects, residential mobility still correlates with a deviation from trend in the latest numbers. In Column [2], we replace the country fixed effects with some variables that are constant at the country-level. The results suggest that the pre-COVID levels are important determinants of the deviation, as shown before. In addition, the level of fiscal spending during COVID has a positive impact on the deviation from trends. This suggests that government transfers supported online spending by increasing consumption, which, in the presence of pandemic restrictions, could mostly be done online. However, richer economies also returned faster to trend once the pandemic receded, as suggested by the negative coefficient on per capita income. A one percentage point (pp) higher residential mobility is associated with a $0.09 \mathrm{pp}$ higher online share gap, while a one pp higher pre-COVID online share is associated with a $0.08 \mathrm{pp}$ higher gap; the effect of fiscal support appears smaller in magnitude with a one pp higher fiscal spending associated with a $0.02 \mathrm{pp}$ higher online gap.

In Column [3], we interact fiscal support during COVID with severity of the restrictions; the interaction term is positive indicating that great fiscal support was associated with higher online shares when restrictions were more severe. Note that the average effect of fiscal spending on online shares (when evaluated at the average level of mobility) remains positive in Column [3]. The average mobility in the sample is $7.5 \%$, therefore the average effect of fiscal spending on e-commerce shares can be computed based on the coefficients in Column (3) as $-0.06+7.5^{\star} 0.01=0.015$, similar to the average effect of fiscal support in Column [2]. We repeat the specifications in Table 2 by splitting the sample into 2020 and 2021; the results are qualitatively similar.

Finally, tourism was a key sector during the pandemic. We focus on its role in Column [4]. This specification has tourism as a \% of GDP, and its interaction with mobility as an additional control. The positive coefficient on tourism (without the interaction) suggests that higher is the country share on tourism the larger is the increase in on-line share with respect to trend; this possibly reflects the fact that countries with a large tourism industry had also a larger pre-existing internet infrastructure which allowed a ramping up of online shares. The interaction term is negative i.e., when external restrictions are higher, the more tourism dependent an economy is, the lower the online shares. Note that when evaluated at the average mobility in the sample, more tourismdependent economies are also associated with lower online shares, probability reflecting travel restrictions during the pandemic phase and more in-person spending during the recovery. 
Table 2. Correlates of deviation in online shares from the predicted pre-COVID trends

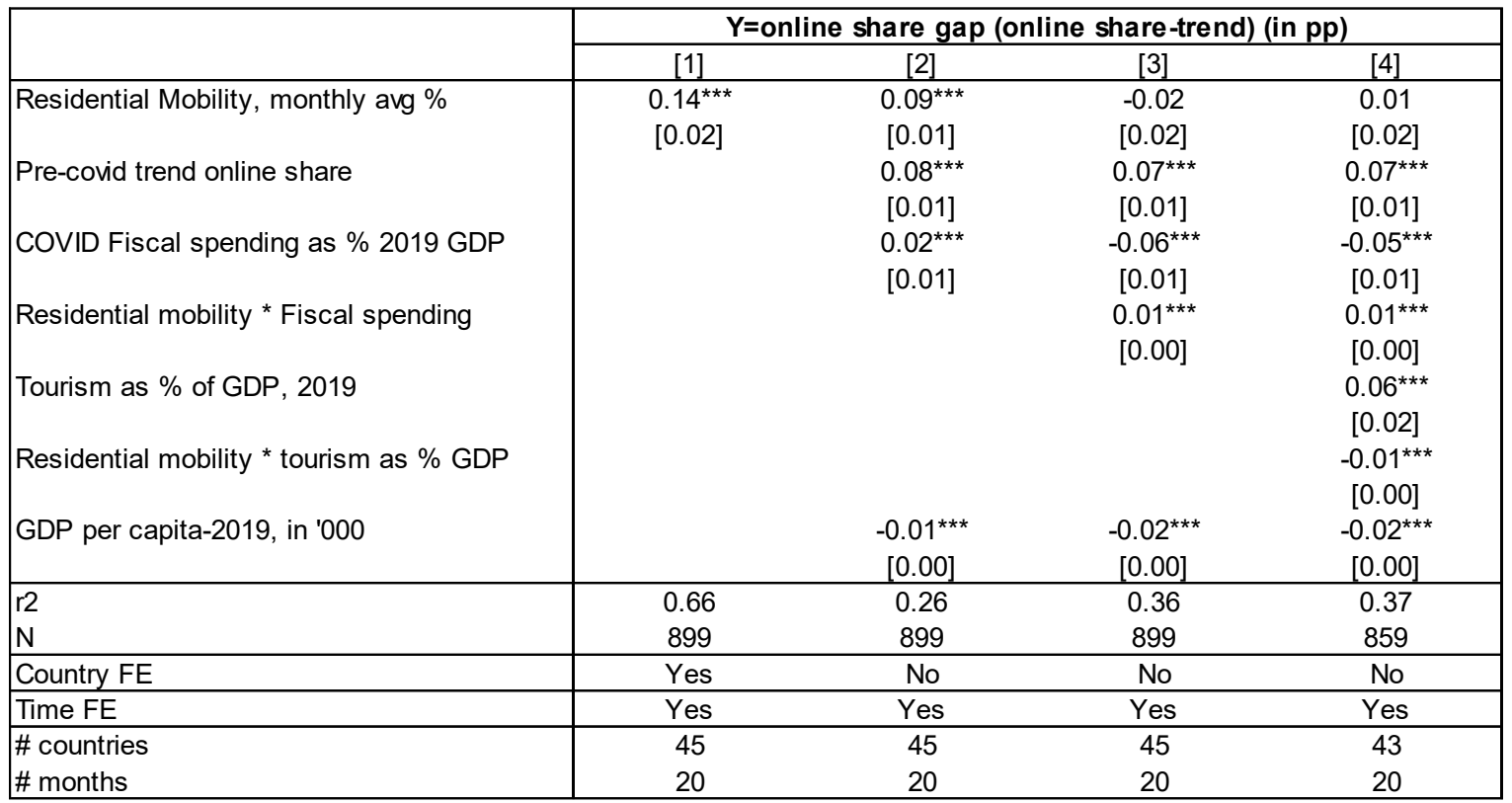

Notes: Robust standard errors in parentheses. ${ }^{* * *},{ }^{* *}$, and ${ }^{*}$ denote statistical significance at 1,5 , and 10 percent levels. Residential mobility on any given day of the week is measured as the percentage change from the baseline value, which is defined as the median value, for the corresponding day of the week, during the 5-week period Jan 3-Feb 6, 2020. Monthly averages of mobility are used in the regressions. Serbia residential mobility data is missing for Jun 2020, hence total observations are 899 and not 900 . GDP per capita is in \$, constant prices, PPP 2017 international dollars, taken from the IMF WEO.

\section{Fact 5. Restaurants, bars, and some retail categories experienced the largest and most persistent increases in online spending shares.}

Table 3 presents a brief snapshot of the share of online spending by sector, which is perhaps most revealing. ${ }^{8}$ It shows the online share by sector pre-COVID, at the peak, at the latest time, and differences between the latest observation and the pre-COVID trend. Among these broad categories, restaurants-bars had the largest increase in online spending shares, rising 14 percentage points from 4\% in 2019 to $18 \%$ at the peak. By September, this was also the sector where the deviation from trend remained the largest, at 2.2 percentage points. At peak values, services and retail had similar percentage point increases, but the deviation remains more persistent for retail, at 0.7 percentage points.

Table 3. Divergence Across Selected Sectors

\begin{tabular}{|l|cccc|}
\hline \multicolumn{1}{|c|}{ Sector } & $\begin{array}{c}\mathbf{2 0 1 9} \\
\text { average }\end{array}$ & $\begin{array}{c}\text { Peak } \\
\text { crisis }\end{array}$ & Latest & $\begin{array}{c}\text { Latest vs } \\
\text { pre-covid } \\
\text { trend }\end{array}$ \\
\hline All Categories & 18 & 23 & 21 & 0.3 \\
Restaurants-Bars & 4 & 18 & 9 & 2.2 \\
Retail & 11 & 17 & 14 & 0.7 \\
Services & 34 & 41 & 36 & -1.0 \\
\hline
\end{tabular}

\footnotetext{
${ }^{8}$ Sectoral averages are created by computing a weighted average of the deviation in online share from the trend at the economysector level, where the weights are the shares of Mastercard spending in the economy-sector as a ratio of global spending in that sector. Notably, there are few sectors (e.g. airlines and travel agencies), with typically very high online penetration; for these we introduce an upper limit on the pre-pandemic time trend, constraining the value below $100 \%$ (as eCommerce shares cannot exceed $100 \%$ ). The industries whose online penetration has achieved the upper limit are included in Table 4 . These include, for example, "mail order", "airline", "travel agencies", and "utilities". As our methodology for estimating online share applies a scaling factor of (total card spending / total consumption), the scaled online shares for these industries will converge to an upper limit of card spend/total consumption when the $100 \%$ threshold is met.
} 
These broad categories mask substantial heterogeneity across subsectors. Table 4 shows the difference between the latest online shares and the pre-crisis trend for 26 disaggregated sectors in our dataset. In particular, department stores, electrical appliance, clothing stores, discount stores, restaurants-bars, and drug stores still report high online shares. Some of these sectors, in particular, restaurant-bars and drug stores, also had low pre-COVID e-commerce shares. On the other hand, the share of online spending in services, specifically professional services, utilities, and recreation, has fallen below its pre-pandemic trend. There are some possible reasons why a larger or more persistent shift to digital did not occur in some of the sectors at the bottom of Table 4. For example, the utility sector has a heavy reliance on mail-in or online payments, where mobility restrictions were less likely to push payments online. In addition, recreational services, which includes gyms, continues to be impacted significantly by COVID. As a result, this impairment has limited the number of re-occurring gym memberships, which are mostly facilitated online.

Table 4. Heterogeneity across sectors in persistence of online shares

\begin{tabular}{|l|ccc|cc|}
\hline \multicolumn{1}{|c|}{ Sector } & $\begin{array}{c}\mathbf{2 0 1 9} \\
\text { average }\end{array}$ & $\begin{array}{c}\text { Peak } \\
\text { crisis }\end{array}$ & Latest & $\begin{array}{c}\text { Latest vs } \\
\text { pre-covid } \\
\text { trend }\end{array}$ & Rank \\
\hline Department Stores & 14 & 36 & 26 & 6.8 & 1 \\
Electric-Appliance & 23 & 39 & 29 & 3.2 & 2 \\
Clothing Stores & 12 & 38 & 16 & 3.0 & 3 \\
Discount Stores & 8 & 17 & 13 & 2.3 & 4 \\
Restaurants-Bars & 4 & 18 & 9 & 2.2 & 5 \\
Drug Stores & 5 & 8 & 7 & 1.9 & 6 \\
Auto Rental & 12 & 20 & 17 & 1.8 & 7 \\
Interior Furnishings & 12 & 25 & 16 & 1.6 & 8 \\
Travel Agencies & 39 & 44 & 43 & 1.3 & 9 \\
Food Stores-Warehouse & 3 & 6 & 5 & 1.1 & 10 \\
Education & 37 & 43 & 41 & 1.0 & 11 \\
Health Care & 18 & 29 & 21 & 0.6 & 12 \\
Airline & 46 & 48 & 48 & 0.6 & 13 \\
Sporting-Toy Stores & 14 & 30 & 17 & 0.4 & 14 \\
Other Services & 32 & 39 & 35 & 0.3 & 15 \\
Gas Stations & 0 & 1 & 1 & 0.2 & 16 \\
Vehicles & 11 & 16 & 12 & -0.1 & 17 \\
Mail Order & 48 & 48 & 48 & -0.2 & 18 \\
Other Retail & 24 & 32 & 26 & -0.3 & 19 \\
Other Transport & 31 & 38 & 33 & -0.6 & 20 \\
Repair Shops & 17 & 22 & 18 & -0.9 & 21 \\
Hotel-Motel & 18 & 27 & 23 & -0.9 & 22 \\
Hardware & 16 & 22 & 17 & -1.3 & 23 \\
Professional Services & 44 & 46 & 45 & -1.4 & 24 \\
Utilities & 44 & 46 & 45 & -1.5 & 25 \\
Recreation & 31 & 40 & 33 & -1.6 & 26 \\
\hline All Categories & 18 & 23 & 21 & 0.3 & \\
\hline
\end{tabular}

Similar to economy-wide results, on average, sectors that were leaders in e-commerce before COVID tended to have larger peak increases in online shares (Figure 6). A difference with our results at the economy-level, however, is that most of the increase during the peak occurred in sectors with a middle-range in online share (hence the slope of the fitted regression is lower compared with Figure 2). In particular, sectors such as clothing, electrical appliances, and sporting goods-toys reported the largest increases compared to the precrisis trend. Some travel service sectors, where the online share was already high before the pandemic, experienced little change in online shares, although these sectors remain heavily impacted by ongoing mobility restrictions. 
Figure 6. Peak versus pre-COVID trend in online spending shares across sectors

Panel A. Peak vs Pre-COVID Trend

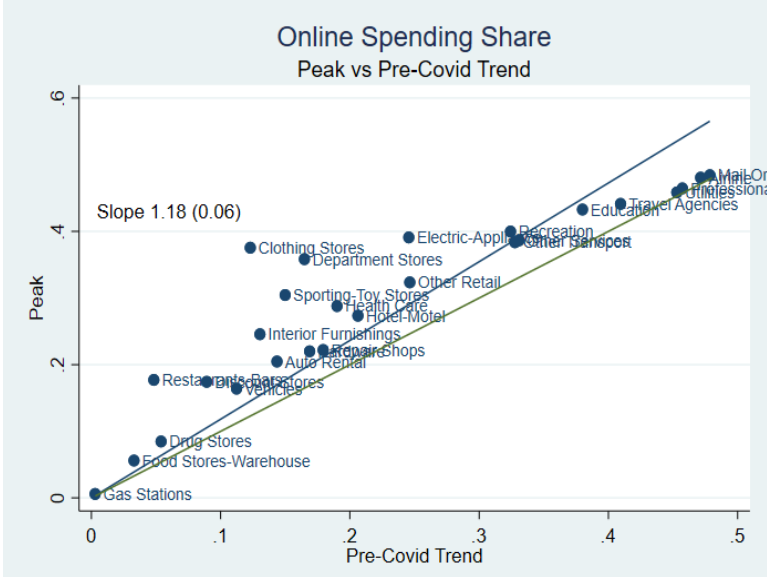

Panel B. Difference between Peak and Pre-COVID Trend vs Pre-COVID Trend

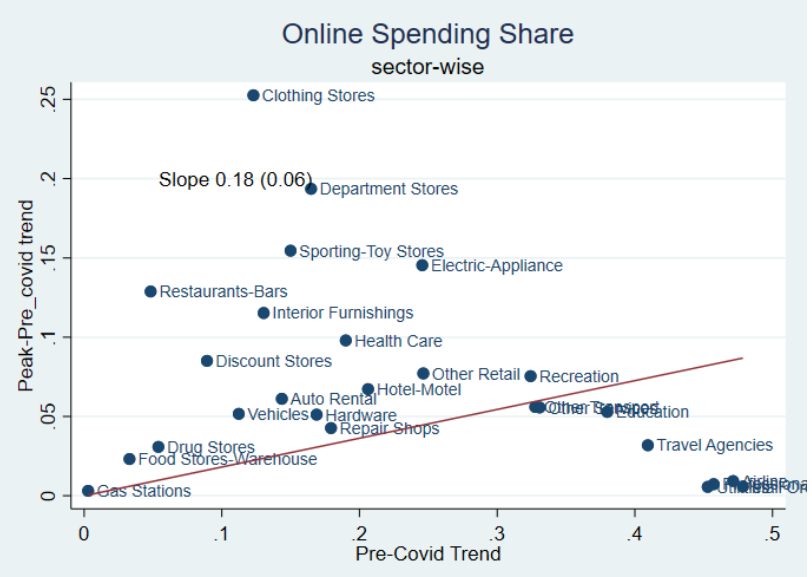

We also find these effects to be (largely) transitory, similar to the evidence across economies (Figure 7), but with the exception of certain sectors such as those in retail, restaurants, and healthcare. The temporary nature looks to be particularly pronounced in industries with higher pre-pandemic shares of e-commerce (where the degree of learning was likely saturated), as well as in industries such as travel and entertainment that are likely still impaired by social mobility effects.

Figure 7. Latest versus pre-COVID trend in online spending shares across sectors
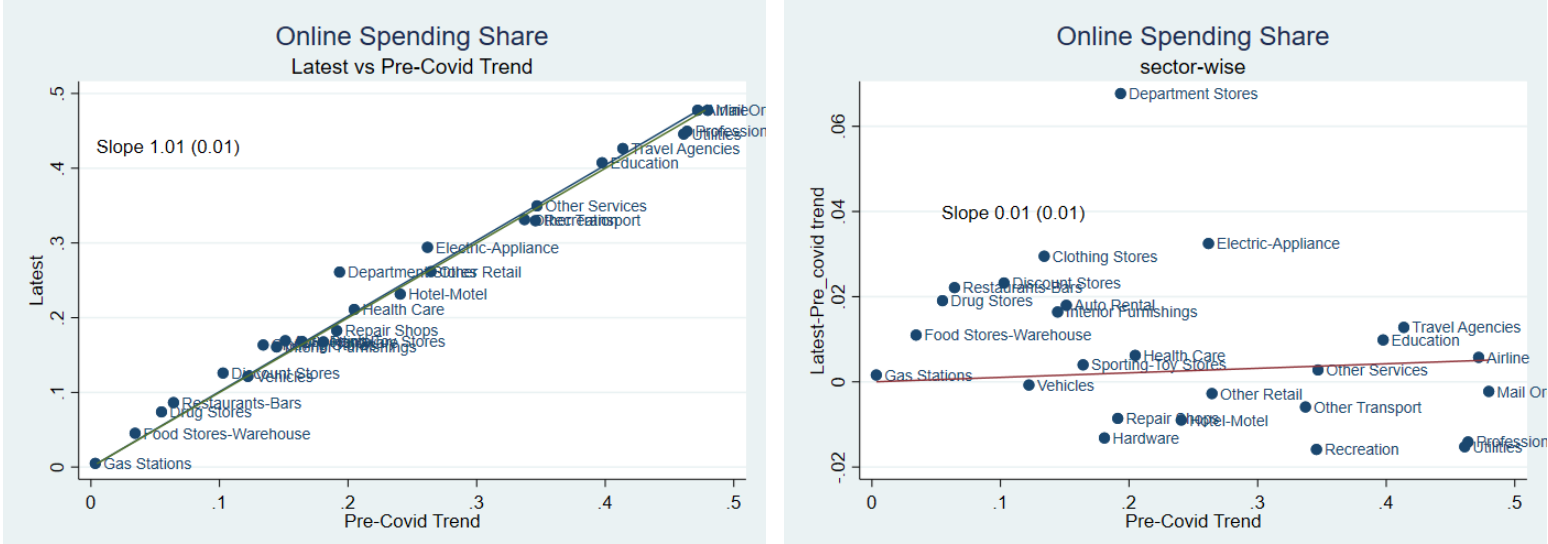

Overall, the sectoral evidence supports the main findings in this paper: i) there is a divergence across sectors in e-commerce shares, with ii) early e-commerce adopters showing the largest peak increases during COVID, but less so than across economies; and (iii) despite the sharp acceleration, the effects appear to be transitory with exceptions in sectors such as in restaurants \& bars, retail and healthcare.

\section{How representative is Mastercard data?}

To estimate the share of online spending in all consumption within an economy, we assumed that Mastercard's online spending is representative of all card transactions and that other online payment methods are either negligible, processed through credit cards, or have similar online share patterns over time. One way to test the validity of these assumptions is to compare our modeled estimates for a subset of economies with alternative results obtained from survey data that incorporates other cards and payment methods. We do this in Figure 8 for the United States and the United Kingdom, where official survey estimates of "online retail spending" are published on a monthly basis by the US Census Bureau and the UK Office of National Statistics. 
The overall dynamic patterns are similar. In particular, the official data also suggests that the online spending share in the United States has returned to the pre-COVID trend levels, while the United Kingdom remains slightly above the trend-predicted levels.

Figure 8: Online shares in retail sales in the United States and the United Kingdom Comparison between modeled estimates and national statistics

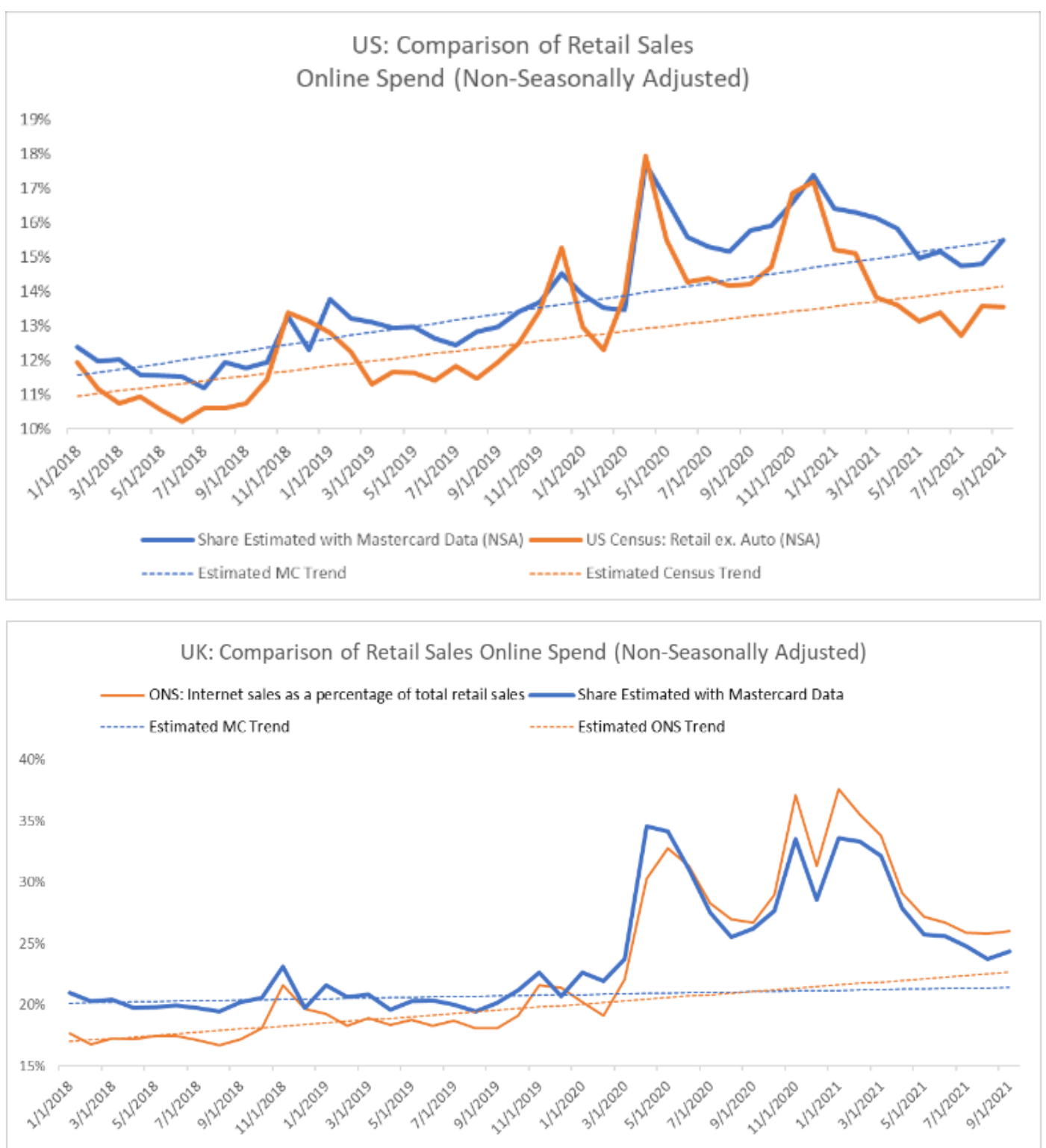




\section{Conclusions}

During the COVID-19 pandemic, online purchases surged in most economies. This paper documents the extent of this surge in a systematic and comparable way, using a unique, large dataset covering 47 economies and 26 sectors. Our main findings are that the share of online spending rose more in economies where ecommerce was already large, and that the increase is reversing as the pandemic recedes. However, when looking at the sector level, we find evidence that the increase in online spending shares is more persistent in retail, restaurants, and healthcare, which are still affected by limited social mobility.

These patterns of divergence and lack of persistence in many cases are surprising. A common story often seen in the press is that the pandemic accelerated the trend towards digitalization, forcing people to learn new digital skills; and this learning was going to stay. Our results support the quick uptake of e-commerce, but the persistence of learning does not appear broad-based, and was seen mostly in sectors with lower pre-pandemic shares of e-commerce (and where the degree of learning was not likely saturated).

What can explain these patterns? During the first phase (surge to the spike), there was a big demand for ecommerce relative to in-person commerce. Economies and sectors that already knew some of the technologies could go online to a larger degree. While the pandemic was a period of forced learning, our results suggest some hysteresis in learning i.e., early adopters could further extend the use of e-commerce within their economies.

At an economy-wide level, for overall consumer spending, mobility plays a crucial role. Based on the latest data, richer economies, where the economic recovery was faster, are closer to the pre-pandemic trends. Meanwhile, economies in later phases of the pandemic, where mobility restrictions are still high, continue to have higher e-commerce penetration. However, there is still a lot of heterogeneity: for roughly half of the economies, it is yet to be seen whether the learning during the pandemic could translate into a higher desired level of online spending.

The scale up in e-commerce appears longer-lasting in some sectors, particularly in restaurants, certain categories of retail, and healthcare. In part, this could reflect the fact that mobility has not fully recovered, along with the types of social interaction required in the sectors. Despite less impaired mobility (e.g., due to holiday foot traffic), the effects appear more long-lasting in the retail sector. ${ }^{9}$ In addition, these are also sectors where digitalization was not particularly high, allowing for more persistent learning to take place. These results do not indicate whether the increase in online spending in these sectors is due to the extensive margin (new customers shopping online) or the intensive margin (old customers shopping even more online). This could also be part of a dynamic learning progress: customers may first learn to shop online in some sectors and later use this new skill in other sectors. With travel and gathering restrictions still in place to differing degrees in economies around the world, the long-term effects are important questions for future research.

9 In evaluating the seasonally adjusted series for the retail sector, among the most seasonal sub-sectors, we estimate that close to $25 \%$ of the peak in the shift online looks like it is persisting by evaluating the current deviation from trend vs. the peak deviation from trend. 


\section{References}

Abraham, Katharine G., Ron S. Jarmin, Brian Moyer, and Matthew D. Shapiro. "Big Data for Twenty-First Century Economic Statistics: The Future Is Now." National Bureau of Economic Research, 2020.

Aladangady, Aditya, Shifrah Aron-Dine, Wendy Dunn, Laura Feiveson, Paul Lengermann, and Claudia Sahm. "From Transactions Data to Economic Statistics: Constructing Real-Time, High-Frequency, Geographic Measures of Consumer Spending." National Bureau of Economic Research, 2019.

Brynjolfsson, Erik and JooHee Oh, "The Attention Economy: Measuring the Value of Free Digital Services on the Internet," 2012.

Carvalho, Vasco M., Stephen Hansen, Álvaro Ortiz, Juan Ramon Garcia, Tomasa Rodrigo, Sevi Rodriguez Mora, and Pep Ruiz de Aguirre. "Tracking the Covid-19 Crisis with High-Resolution Transaction Data" (2020).

Cavallo, Alberto. "Online and Official Price Indexes: Measuring Argentina's Inflation." Journal of Monetary Economics 60, no. 2 (2013): 152-65.

Cavallo, Alberto. "More Amazon Effects: Online Competition and Pricing Behaviors." Jackson Hole Economic Symposium Conference Proceedings - Federal Reserve Bank of Kansas City, 2018.

Choi, Hyunyoung, and Hal Varian. "Predicting the Present with Google Trends." Economic Record 88 (2012): 2-9.

Couture, Victor, Benjamin Faber, Yizhen Gu, and Lizhi Liu, "Connecting the Countryside via E-Commerce: Evidence from China," American Economic Review: Insights, 2020.

Dolfen, Paul, Liran Einav, Peter J. Klenow, Benjamin Klopack, Jonathan D. Levin, and Larry Levin, 2020, "Assessing the Gains from E-Commerce", mimeo, Stanford University, May 2020.

Einav, Liran, and Jonathan Levin. "The Data Revolution and Economic Analysis." Innovation Policy and the Economy 14, no. 1 (2014): 1-24.

Glaeser, Edward L., Hyunjin Kim, and Michael Luca. "Nowcasting the Local Economy: Using Yelp Data to Measure Economic Activity." National Bureau of Economic Research, 2017.

Goolsbee, Austan and Peter J. Klenow, "Valuing Consumer Products by the Time Spent Using Them: An Application to the Internet," American Economic Review, 2006, 96 (2), 108-113.

Jo, Yoon J., Misaki Matsumura, and David E. Weinstein, "The Impact of ECommerce on Relative Prices and Consumer Welfare," 2019. National Bureau of Economic Research Working Paper 26506.

Kinda, 2019, "E-commerce as a Potential New Engine for Growth in Asia", IMF Working Paper Working Paper No. 19/135, July 1, 2019.

Mian, Atif, Kamalesh Rao, and Amir Sufi. "Household Balance Sheets, Consumption, and the Economic Slump." The Quarterly Journal of Economics 128, no. 4 (2013): 1687-1726.

Reinsdorf, Marshall and Paul Schreyer (2020), "Measuring consumer inflation in a digital economy", in Barbara M. Fraumeni eds Measuring Economic Growth and Productivity, Academic Press, 2020, Pages 339-362.

Syverson, Chad, "Challenges to Mismeasurement Explanations for the US Productivity Slowdown," Journal of Economic Perspectives, 2017, 31 (2), 165-86.

Turrell, Arthur, Bradley J. Speigner, Jyldyz Djumalieva, David Copple, and James Thurgood. "Transforming Naturally Occurring Text Data into Economic Statistics: The Case of Online Job Vacancy Postings." National Bureau of Economic Research, 2019.

Varian, Hal, "The Value of the Internet Now and in the Future," The Economist, 2013. 
Table A1. Summary Statistics for Variables in Table 2

\begin{tabular}{|lrrrrr|}
\hline \multicolumn{1}{|c}{ Variable } & \multicolumn{1}{c}{ Obs } & \multicolumn{1}{c}{ Mean } & Std. Dev. & \multicolumn{1}{c|}{ Min } & \multicolumn{1}{c|}{ Max } \\
\hline Online share gap (online share-trend) (in pp), NSA & 899 & 0.9 & 2.4 & -7.0 & 15.0 \\
\hline Residential Mobility, \% & 899 & 7.5 & 7.3 & -8.8 & 40.3 \\
Pre-covid trend online share & 899 & 12.0 & 10.2 & 1.2 & 34.8 \\
COVID Fiscal spending as \% 2019 GDP & 899 & 12.9 & 9.9 & 0.6 & 43.4 \\
\hline GDP per capita-2019, in '000 & 899 & 35.6 & 23.7 & 2.8 & 115.6 \\
Residential mobility * Fiscal spending, 2019 & 899 & 96.4 & 132.4 & -149.8 & 1228.0 \\
\hline
\end{tabular}

\section{Appendix A: Summary of Data in Mastercard Transaction-Level Data}

Payments occur through various channels - cash, card, check, deposits among others. In this paper, we evaluate aggregated $\&$ anonymized card transactions across the Mastercard network.

While the retail and services sector are generally well-represented through carded transactions, certain segments such as vehicle sales, are not captured, as the primary form of payment for vehicles are deposits as opposed to cards.

As the primary form of payment for online transactions are by card, there is an inherent payment-form bias in evaluating spending trends of a payment network. To adjust for this bias, we estimate online shares in the universe, detailed in Appendix B.

A related database from Mastercard was used by Mian et al (2013).

\section{How big is Mastercard?}

The Mastercard network has a presence in 210 countries and territories, connected to 20,000 financial institutions and over 80 million merchant locations with more than 2.9 billion cards in force. Switching roughly 100 billion transactions in a year.

In Q3 2021, the total value of purchases made and cash disbursements obtained on Mastercard cards was nearly 2 trillion dollars.

\section{What type of data can be seen at the transaction level?}

- Date \& time: the date and time in which the transaction occurred

- Type of card: whether the card is a credit, debit, or pre-paid card

- Merchant location: what is the address on record for the merchant where the transaction took place?

- Industry classification: what industry is the merchant classified as

- Channel: whether the payment was an online or brick \& mortar transaction

- Transaction amount: the value of the transaction made

\section{What type of data cannot be seen at the transaction level?}

- Cardholder information: Mastercard does not see details around the cardholder, such as their location, income, or account balances.

- Item-level / SKU-level breakout of the purchase being made. Mastercard sees a single payment amount for all goods purchased.

\section{How is Mastercard data used in this paper?}

For this paper, we leveraged aggregated \& anonymized transaction level data at an industry \& sector level by market, measured as a monthly time series. Using the sum of transactions that occur each month for point of interaction/card present and online sales, we estimate share of online spend by economy. 


\section{Appendix B: Estimation of Online Shares in the Universe}

\section{Online shares for overall economy}

Say there are only two cards MC and Visa (V). We assume for simplicity that online transactions can happen only through cards (in reality online transactions can also happen through say e-wallet etc.)

Our aim is to compute

$$
\begin{gathered}
S_{c, t} \text { Universe }=\frac{\text { Total online spending }}{\text { Total consumption }}=\frac{O S}{C}=\frac{M C O}{C}+\frac{V O}{C} \\
=\frac{M C O}{M C} * \frac{M C}{C \text { ard }} * \frac{\text { Card }}{C}+\frac{V O}{V} * \frac{V}{\text { Card }} * \frac{\text { Card }}{C}
\end{gathered}
$$

Assume $\frac{M C O}{M C}=\frac{V O}{V}=s_{c, t}{ }^{M C}$

$$
\begin{gathered}
s_{c, t} \text { Universe }=s_{C, t}{ }^{M C} * \frac{\text { Card }}{C}\left(\frac{M C}{\text { Card }}+\frac{V}{\text { Card }}\right)=s_{C, t}{ }^{M C} * \frac{\text { Card }}{C} \\
\text { assuming } \frac{M C}{\text { Card }}+\frac{V}{\text { Card }}=1
\end{gathered}
$$

\section{Online shares at sectoral level}

Say there are only two cards MC and Visa (V). We assume for simplicity that online transactions can happen only through cards (in reality online transactions could also happen through say e-wallet etc.)

Our aim is to compute

$$
\begin{aligned}
S_{c, I, t} \text { Universe } & =\frac{\text { Total online spending in industry } I}{\text { Total consumption in industry I }}=\frac{O S^{I}}{C^{I}}=\frac{M C O^{I}}{C^{I}}+\frac{V O^{I}}{C^{I}} \\
& =\frac{M C O^{I}}{M C^{I}} * \frac{M C^{I}}{\operatorname{Card}^{I}} * \frac{\operatorname{Card}^{I}}{C^{I}}+\frac{V O^{I}}{V^{I}} * \frac{V^{I}}{\operatorname{Card}^{I}} * \frac{\operatorname{Card}^{I}}{C^{I}}
\end{aligned}
$$

Assume $\frac{M C O^{I}}{M C^{I}}=\frac{V O^{I}}{V^{I}}=s_{C, I, t}{ }^{M C} \quad$, so that MC's online share in industry I is representative

$$
\begin{gathered}
s_{C, I, t}{ }^{\text {Universe }}=s_{C, I, t}{ }^{M C} * \frac{\operatorname{Card}^{I}}{C^{I}}\left(\frac{M C^{I}}{\operatorname{Card}^{I}}+\frac{V^{I}}{\operatorname{Card}^{I}}\right)=s_{C, I, t}{ }^{M C} * \frac{\operatorname{Card}^{I}}{C^{I}} \\
\text { assuming } \frac{M C^{I}}{\operatorname{Card}^{I}}+\frac{V^{I}}{\operatorname{Card}^{I}}=1
\end{gathered}
$$




\section{Appendix C: Mastercard's Market Share Cut-off}

To increase the chances of having a representative sample in the paper we limited our data to economies where Mastercard has a significant market share. Changing this cutoff value has little impact on our results. To show this, we computed the online share for economies where Mastercard has a small share of the card market and compared it to the results we can obtain from the 47 economies included in our sample. Figure $\mathrm{C} 1$ shows that online shares are highly correlated between these two groups, with a correlation coefficient of 0.97 .

Figure C1: Online shares in economies where Mastercard has $>=20 \%$ and $<20 \%$ market share.

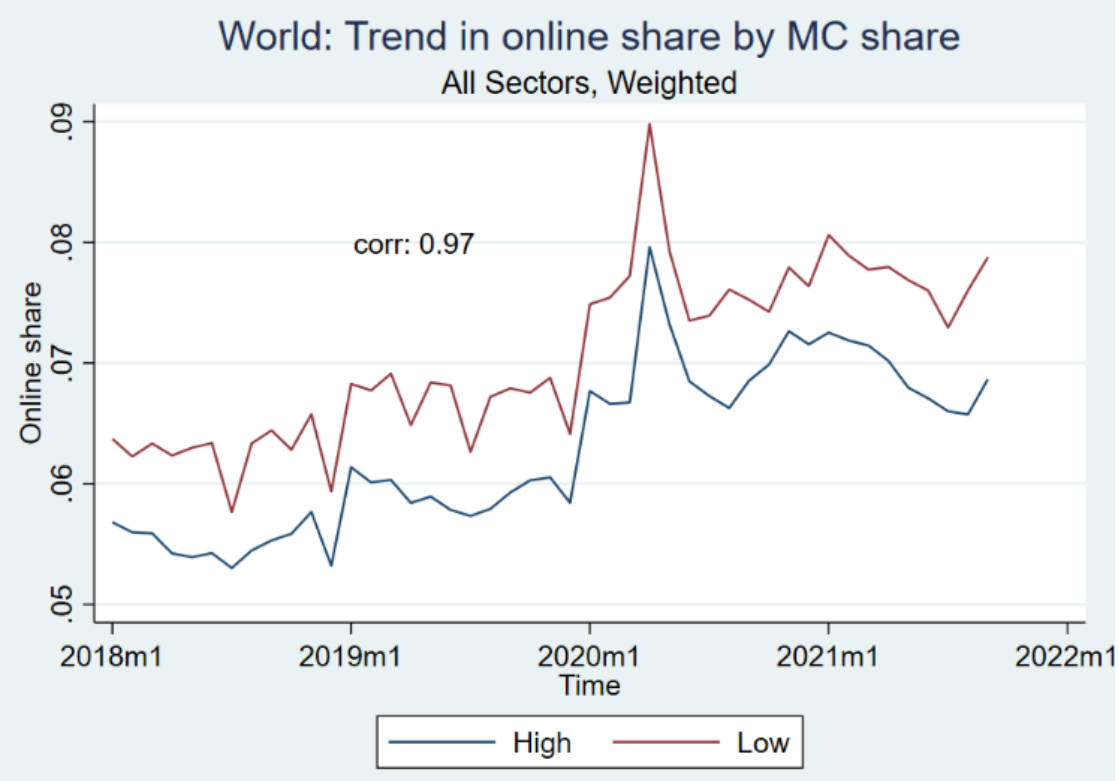




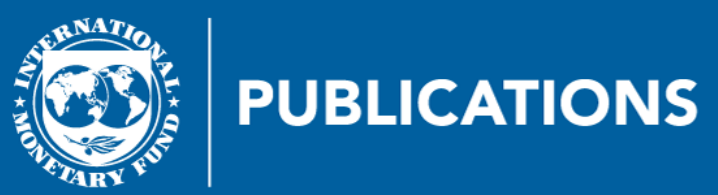

E-commerce During Covid: Stylized Facts from 47 Economies Working Paper No.

[WP/YYYY/\#\#\#] 